\title{
Environmental and genotypic effects on stomatal control of evapotranspiration from irrigated rice
}

\author{
Shinichi TAKAMI*, ${ }^{\dagger}$, Tetsuo SAKURATANI**, and, Takeshi HORIE*** \\ $\left(\begin{array}{c}* \text { Laboratory for Environmental Resources, Miyazaki, 880-0056 } \\ * * \text { Professor Emeritus, Kyoto University, Sapporo, 060-0009 } \\ * * * \text { National Agriculture and Food Research Organization, Tsukuba, 305-8517 }\end{array}\right)$
}

\begin{abstract}
Evapotranspiration (ET) rates from irrigated rice differ across environments and cultivars. To quantify these differences, we developed a computational model for prediction of crop ET of irrigated rice from meteorological variables and crop parameters. The model was based on a generalized combination formula and a stomatal response function derived from a controlled environment. Model predictions compared favorably with ET rates from crops measured by microlysimetry. Using this model, we simulated ET rates from hypothetical rice crops under different climatic conditions. Regardless of cultivars and leaf area index (LAI), all the crops demonstrated higher ET rates relative to the potential in a humid temperate climate than in an arid tropical climate. Strong winds generally prevailing in a tropical dry climate make stomatal control of ET in this climate more significant than that in a calm temperate climate. Furthermore, a cultivar with smaller minimum crop resistance (Rmin) always evaporated at a higher rate than a cultivar with larger Rmin when the same atmospheric demand was imposed. Such a difference was more distinct in the dry tropical conditions than in the humid temperate conditions. These findings agree with observations so far reported for irrigated rice. Thus, we conclude that our numerical model is capable of accounting for the effects of cultivars and environments on ET rates from irrigated rice.
\end{abstract}

Key words: Generalized combination formula, Maximum leaf conductance Microlysimetry, Numerical model, Stomatal response function.

\section{Introduction}

Stomata exert varying degree of control on evapotranspiration (ET) from irrigated rice across environments and genotypes. Takami and O’Toole (1983), for instance, found that the stomatal control was more significant in a dry, tropical environment than in a humid, temperate environment. Actual ET relative to the potential was about $82 \%$ in the dry tropical conditions, approximately $10 \%$ lower than that in the humid temperate conditions.

In addition to environmental effects, Horie et al. (2006) detected significant genotypic differences in the canopy-air temperature difference among wide

Received; October 3, 2012.

Accepted; January 8, 2013.

${ }^{\dagger}$ Corresponding Author: takamicatv@gmail.com range of rice genotypes. High-yielding crossbreds generally showed larger canopy conductance and temperature depression than the other genotypes. Thus, the ET rates from these crossbreds were inferred to be higher than those from the others. This finding agrees with earlier observations by Sakuratani and Horie (1985). They found that ET rates from two improved indica hybrids were higher than the rates from a japonica cultivar under higher evaporative demands. Ecophysiological mechanisms in environmental and genotypic effects so far observed on ET rates from irrigated rice are not clear, however.

The objective of this study was to quantitatively demonstrate how the stomatal control on ET from irrigated rice varies across environments and cultivars. There exist a number of rice models that are capable of simulating crop development, growth and yield. Among them, ORYZA 2000 (Bouman et al., 2001) 
and CERES-rice (Jones et al., 2003) are the most comprehensive as well as practical, and therefore used extensively in various locations and situations. Both models can simulate water use as well. However, these models are unsuited to our present purpose, because stomatal control on water use is not considered explicitly. Thus, we developed a computational model for prediction of ET rates from meteorological variables and crop parameters for irrigated rice as described in the Methods section. The model was first tested by field experimentation and subsequently used to simulate the ET rates to observe the effects of stomatal characteristics and environmental conditions.

\section{Methods}

First, we developed a numerical model, by coupling a leaf stomatal response function (SRF) to the generalized combination formula (Penman-Monteith equation, PME). Such approach as this is recognized as a simple but valid example of a process-based model that includes the stomatal behavior, as well as a basic representation of the canopy feature (Gerosa et al., 2012). The SRF we used is the one proposed by Horie (1980). We chose it for the following reasons. First, it employs a multiplicative model that has been used, among numerous SRFs (Damour et al., 2010), most successfully since it was first proposed by Jarvis (1976) and further revised by Stewart (1988). Second, the parameters in this SRF are also derived from controlled environmental studies. The SRF of our choice is therefore more general and flexible. Parameters in most SRFs are usually fitted to field data using technique such as nonlinear least square regression or boundary-line analysis (e.g., Gerosa et al., 2012) . Third, our SRF considers all the necessary environmental variables for irrigated rice.

The model so constructed was then tested against ET data from the irrigated rice fields. The SRF we adopted has not been tested explicitly in the field. Having verified the model, we performed simulations with the hypothetical rice crops to see the environmental and genotypic effects on ET.

\subsection{Modeling}

We made the following basic assumptions: (i) Crop is analogous to an "equivalent" single leaf, that is, "a whole canopy" or "a big leaf” concept (Monteith 1965; Gerosa et al., 2012). (ii) Soil is completely wet or submerged. (iii) Crop is uniform and dense. We use the PME to determine the ET rate $(E)$ :

$$
E=E o(1+\varepsilon) /(1+\varepsilon+R c / R a)
$$

where $E o(\mathrm{~mm} / \mathrm{h})$ is the potential ET rate, $\varepsilon$ the dimensionless constant depending on the temperature, $R \mathrm{c}$ $(\mathrm{s} / \mathrm{m})$ the canopy or crop resistance, $R \mathrm{a}(\mathrm{s} / \mathrm{m})$ the aerodynamic resistance of the crop. For rice, $R c$ can be approximated by the following equation (Monteith and Unsworth, 2008) :

$$
R \mathrm{c}=R S /(2 \cdot L A I)
$$

where $R S$ is the stomatal resistance for the projected area of the leaf $(\mathrm{s} / \mathrm{m})$, and $L A I$ the leaf area index. $R S$, though called the stomatal resistance in this study, includes the cuticular resistance and the leaf boundary layer resistance as well.

SRF used in this study is as follows (Horie, 1980):

$$
\begin{aligned}
R S= & (R \min +(R \max -R \min ) \exp (-b \cdot P A R)) \\
\cdot f & (D L) \cdot \mathrm{f}(T L) \\
& \mathrm{f}(D L)=1.0 \quad \text { for } D L<D L c \text { or } \\
& \mathrm{f}(D L)=1.0-a(D L-D L c) \quad \text { for } D L \geqq D L c \\
& \mathrm{f}(T L)=1.0-c(T L-T L c)
\end{aligned}
$$

The parameters $a, b$, and $c$ are respectively the one to determine $D L, P A R$ and $T L$ dependence on $R S$. The parameter $D L C$ and $T L C$ are threshold values for $D L$ and $T L$, respectively. Also, Rmin is the minimum value of $R S$ when $P A R$ is varied under the conditions $D L$ at $D L C$ and $T L$ at $T L C$. In rice, $C$ was found to be zero, so that $\mathrm{f}(T L)$ is reduced to 1 .

This expression was derived from the controlled experimental studies, in which the $\mathrm{CO}_{2}$ concentration was kept at normal and the plants were well watered. Consequently, the governing factors considered as important were the photosynthetically active radiation $(P A R)$, the leaf temperature $(T L)$ and the leaf-air vapor concentration difference $(D L)$. Effect of the leaf water potential was not included, but considered indirectly through $D L$. A non-linear model of the form $R S=R \min \cdot \mathrm{f}(P A R) \cdot \mathrm{f}(T L) \cdot \mathrm{f}(D L)$ was used to combine these factors.

By definition the leaf-air vapor concentration difference $D L$ is written as 


$$
D L=H o-H a
$$

where $\mathrm{Ho}\left(\mathrm{g} / \mathrm{m}^{3}\right)$ is the vapor concentration at the evaporating site and $\mathrm{Ha}\left(\mathrm{g} / \mathrm{m}^{3}\right)$ the humidity of the air. Using the Penman transformation (e.g., Campbell and Norman, 1998), this relation can be approximated by

$$
D L=d a+R a \cdot s \cdot S / C v
$$

where $d a\left(\mathrm{~g} / \mathrm{m}^{3}\right)$ is the saturation deficit of the air, $S$ the sensible heat flux density, $s$ the slope of the saturation vapor concentration versus temperature curve and $C v$ the volumetric heat capacity of the air. $S$ in Eq. (4) and $E$ in Eq. (1) are bound by the energy balance as

$$
S+\lambda E=F
$$

where $\lambda$ is the latent heat of vaporization, and the available energy $F\left(\mathrm{~W} / \mathrm{m}^{2}\right)$ is the difference between the net radiant energy $(R n)$ and the ground heat flux $(G)$, i.e., $F=R n-G$.

The set of Eqs. (1) through (5) is our crop ET model (CEM). Given five external variables (Eo, Ra, $P A R, d a$ and $F$ ) and seven system parameters ( $L A I$, Rmax, Rmin, DLc, TLc, $a$ and $b$ ), Eqs. (1) through (5) can be solved for five unknowns $E, R c, R S, D L$ and $S$ numerically.

To determine $E$ and the other four state variables from environmental variables usually measured, we shall introduce several supplemental relations. The first one is the well-known Penman-Van Bavel equation to determine Eo (Van Bavel, 1966) :

$$
\lambda E o=\frac{\varepsilon F+\lambda d a / R a}{1+\varepsilon}
$$

$R a$ in Eq. (6) is derived from the wind function as

$$
R a=\frac{[\ln ((Z-d) / d)]^{2}}{0.168 U a}
$$

where $U a(\mathrm{~m} / \mathrm{s})$ is the wind speed at the height of $Z$ $(\mathrm{m}), d(\mathrm{~m})$ the zero-plane displacement, and $Z o(\mathrm{~m})$ the roughness height (e.g., Monteith and Unsworth, 2008). For simplicity, we have assumed the neutral conditions of the atmosphere. Additionally, we use the empirical relations to estimate $F$ from the global irradiance $I\left(\mathrm{~W} / \mathrm{m}^{2}\right)$ through $R n$ and $G$ estimated respectively as follows:

$$
R n=0.62 I
$$

and

$$
G=0.01 I
$$

Eq. (8) was obtained from the measurements over an irrigated rice crop as a seasonal average, whereas Eq. (9) is an estimate based on a diurnal measurement (Uchijima, 1976). PAR was also estimated from I empirically (Monteith and Unsworth, 2008):

$$
P A R=0.50 I
$$

Then, the environmental variables required to solve the CEM are the global irradiance $I\left(\mathrm{~W} / \mathrm{m}^{2}\right)$, the air temperature $T a\left({ }^{\circ} \mathrm{C}\right)$, the saturation deficit $d a\left(\mathrm{~g} / \mathrm{m}^{3}\right)$ and the wind speed $U a(\mathrm{~m} / \mathrm{s})$, all to be measured at a single level above the canopy surface.

\subsection{Experimentation}

We used data from two field experiments to test our model. One was conducted at the International Rice Research Institute (IRRI), Los Baños, Philippines during the dry season in 1979. The other was conducted at the National Institute for Agricultural Sciences (NIAS), Tsukuba, Japan during the summer in 1982. Details of each experiment are found elsewhere (Takami and O'Tool, 1983; Sakuratani and Horie, 1985).

\section{IRRI Experiment}

We measured ET, attendant micrometeorological variables and crop parameters in an irrigated rice field of IR36, an improved indica cultivar. Intensive measurements were made over 2 to 3 days during three periods: March 26 to 27 (the maximum tillering stage), April 20 to 21 (the flowering stage) and May 8 to 10 (the grain-filling stage). Two microlysimeters replicated three times were used to measure ET (Tomar and O’Toole, 1980). Readings were taken at two-hour intervals during the daytime, and once again the next morning.

Global irradiance $\left(I, \mathrm{~W} / \mathrm{m}^{2}\right)$, dry $\left(\mathrm{Ta},{ }^{\circ} \mathrm{C}\right)$ and wet $\left(\mathrm{Tw},{ }^{\circ} \mathrm{C}\right.$ ) bulb temperatures at the height of $1 \mathrm{~m}$ above the ground and wind speed $(U a, \mathrm{~m} / \mathrm{s})$ at $1.25 \mathrm{~m}$ were measured in the rice field every hour on the hour. Leaf area index $\left(\operatorname{LAI}\left(\mathrm{m}^{2} / \mathrm{m}^{2}\right)\right)$ and canopy height $(h, \mathrm{~cm})$ were followed during the course of crop development. NIAS experiment

We conducted similar measurements in the rice field of NIAS during the period between August 31 to September 1 (the grain-filling period), using two cultivars, IR 36 and Nipponbare (japonica). Two lysimeters were installed in each cultivar. Readings were taken 
every hour, and ET rates were determined for a $2 \mathrm{hr}$ period. Meteorological variables, basically the same as in IRRI experiment, were collected at the nearby meteorological station, $\mathrm{Ta}$ and $\mathrm{Td}$ (the dew point temperature, ${ }^{\circ} \mathrm{C}$ ) at $1.5 \mathrm{~m}$ and $U a$ at $10 \mathrm{~m}$ above the ground being measured.

Other data

Values for the coefficients of the SRF are those obtained for Nipponbare (japonica) in the controlled environment (Horie, 1980). For IR36 (indica), we assume that it has the same values as Nipponbare, except Rmin (Table 1). This is based on the field observation that Rmin of Ginnen (indica) was approximately half that of a japonica rice and $R S$ of both cultivars changed in parallel diurnally (Maruyama et al., 1985).

Aerodynamic properties of the crop ( $d$ and $Z o, m$ )

Table 1. Characteristics of stomatal response of two rice cultivars.

\begin{tabular}{lclll}
\hline Term & Units & \multicolumn{1}{c}{ Definition } & \multicolumn{1}{c}{ Cv J } & Cv I \\
\hline$R \min$ & $\mathrm{s} / \mathrm{m}$ & Minimum leaf resistance & 170 & 70 \\
Rmax & $\mathrm{s} / \mathrm{m}$ & Maximum leaf resistance & 4500 & 4500 \\
$a$ & $\mathrm{~m}^{3} / \mathrm{g}$ & Humidity parameter & 0.05 & 0.05 \\
$b$ & $1 / \mathrm{K}$ & $P A R$ parameter & 0.0431 & 0.0431 \\
$D L C$ & $\mathrm{~g} / \mathrm{m}^{3}$ & $D L$ threshold value & 11 & 11 \\
\hline
\end{tabular}

were estimated from $h$ using an empirical relation (Uchijima, 1976) :

$$
\begin{aligned}
& d=\left(1.04 h^{0.92}\right) / 100 \\
& Z o=\left(0.025 h^{1.32}\right) / 100
\end{aligned}
$$

\subsection{Simulation}

Simulation was made with four hypothetical crops: (i) cultivar (Cv) J with $L A I$ of 2, (ii) Cv J with $L A I$ of 4, (iii) Cv I with $L A I$ of 2, and (iv) Cv I with $L A I$ of 4. $\mathrm{Cv} \mathrm{J}$ was assumed to have the same plant characteristics as Nipponbare, whereas Cv I corresponded to IR36, as defined in Table 1 . In other words, two cultivars were assumed to differ in the one parameter Rmin in SRF alone. Crop height $h$ was assumed $1.0 \mathrm{~m}$ for all the crops. Thus all the crops had the same aerodynamic properties.

These crops were assumed to grow under two weather conditions (Table 2): (i) a sunny and windy day, representing a dry, tropical climate (IRRI May 9, 1979) and (ii) a sunny and calm day, representing a summer of a humid, temperate climate (NIAS September 1, 1982). Using the CEM as described before, we computed hourly $E o$ and $E$ for each of the four crops under the two weather conditions. Hourly Eo and

Table 2. Daytime hourly meteorological data for simulation.

May 9,1979 for IRRI and September 1,1982 for NIAS.

\begin{tabular}{rrrrrrrrc}
\hline Time & \multicolumn{2}{c}{$\begin{array}{c}\text { Global } \\
\text { irradiance } \\
\left(\mathrm{W} / \mathrm{m}^{2}\right)\end{array}$} & $\begin{array}{c}c \\
\text { temperature } \\
\left({ }^{\circ} \mathrm{C}\right)\end{array}$ & \multicolumn{2}{c}{$\begin{array}{c}\text { Dir } \\
\left({ }^{\circ} \mathrm{C}\right)\end{array}$} & $\begin{array}{c}\text { Wewpoint } \\
\text { speed } \\
(\mathrm{m} / \mathrm{s})\end{array}$ \\
\cline { 2 - 9 } & IRRI & NIAS & IRRI & NIAS & IRRI & NIAS & IRRI & NIAS \\
\hline 6 & 68 & 175 & 27.0 & 22.1 & 21.4 & 21.8 & 1.0 & 0.5 \\
7 & 272 & 350 & 28.0 & 23.5 & 21.8 & 22.6 & 1.2 & 0.7 \\
8 & 503 & 548 & 29.2 & 25.1 & 22.3 & 21.9 & 1.9 & 0.7 \\
9 & 677 & 689 & 29.6 & 26.9 & 23.4 & 20.0 & 1.9 & 0.9 \\
10 & 805 & 759 & 30.8 & 27.3 & 23.6 & 19.6 & 2.0 & 0.6 \\
11 & 892 & 805 & 32.8 & 28.3 & 21.3 & 20.4 & 2.7 & 1.4 \\
12 & 977 & 817 & 33.2 & 27.8 & 21.7 & 20.1 & 2.9 & 1.3 \\
13 & 927 & 724 & 33.2 & 28.4 & 21.0 & 19.7 & 3.0 & 1.3 \\
14 & 795 & 607 & 34.0 & 28.4 & 22.4 & 19.2 & 2.8 & 1.3 \\
15 & 685 & 443 & 33.8 & 28.3 & 22.9 & 18.9 & 3.2 & 1.4 \\
16 & 482 & 245 & 32.0 & 27.8 & 22.8 & 19.3 & 3.6 & 1.4 \\
17 & 236 & 70 & 29.6 & 26.5 & 21.9 & 20.4 & 2.8 & 1.6 \\
18 & 57 & 12 & 28.4 & 24.8 & 22.5 & 21.1 & 1.6 & 1.5 \\
$\#$ & 26.6 & 22.5 & 30.9 & 26.6 & 22.2 & 20.3 & 2.4 & 1.1 \\
\hline
\end{tabular}

\#Daily total for the global irradiance $\left(\mathrm{MJ} / \mathrm{m}^{2}\right)$ and daytime average for the rest of meteorological variables. 
$E$ were integrated to give daytime totals.

Additionally, we computed daytime average $R c$ $(\overline{R C})$ by

$$
\overline{R c}=(1+\varepsilon)(E o / E-1) R a
$$

where $\varepsilon$ and $R a$ are corresponding to the air temperature and wind speed averaged over the daytime period.

\section{Results and Discussion}

\subsection{Verification of the model}

Measured ET rates at NIAS on September 1, 1982 were higher in IR36 than in Nipponbare throughout most of the day, so that the daily total was $8.2 \pm 0.73$ $\mathrm{mm}$ (mean $\pm \mathrm{SE}$ ) for IR36 and $7.6 \pm 0.55 \mathrm{~mm}$ for Nipponbare (Fig. 1). Hourly comparisons of measured and calculated ET show that the calculated ET rates were in an acceptable agreement with the measured ones, except in the mornings when the atmospheric demand was low. Similar results were obtained for August 31 (figure not shown), but the differences between the two cultivars were much less distinct because of the lower atmospheric demand. Daily total of measured ET were $4.6 \pm 0.50 \mathrm{~mm}$ for IR36 and $4.5 \pm 0.33 \mathrm{~mm}$ for Nipponbare.
Data are also available from the IRRI experiment for comparison between the measured and the calculated ET. The data set from this experiment, together with the one from the NIAS experiment, was used to make hourly as well as daily comparisons. The relation thus obtained was close to $1: 1$, although on an hourly basis the scatter of data points was large (Fig. 2a). Comparison on a longer time scale (daytime total) shows much closer agreement between the measured and the computed ET (Fig. 2b).

Less satisfactory agreement between measured and computed values on an hourly basis could be due to the following reasons. First, the net radiation and the soil heat flow were estimated rather than measured. These estimates are based on the empirical relations established for daily or longer period average conditions. Thus, in principle at least, they are unsuited for the use of hourly or instantaneous computations (Van Bavel, 1966). Likewise, wind function to compute $R a$ could be in some error, since the aerodynamic properties of the crop were estimated from crop height. As demonstrated in the next section, $R a$ thus the aerodynamic parameters are important to determine ET relative to the potential ET. Furthermore, the precision of the

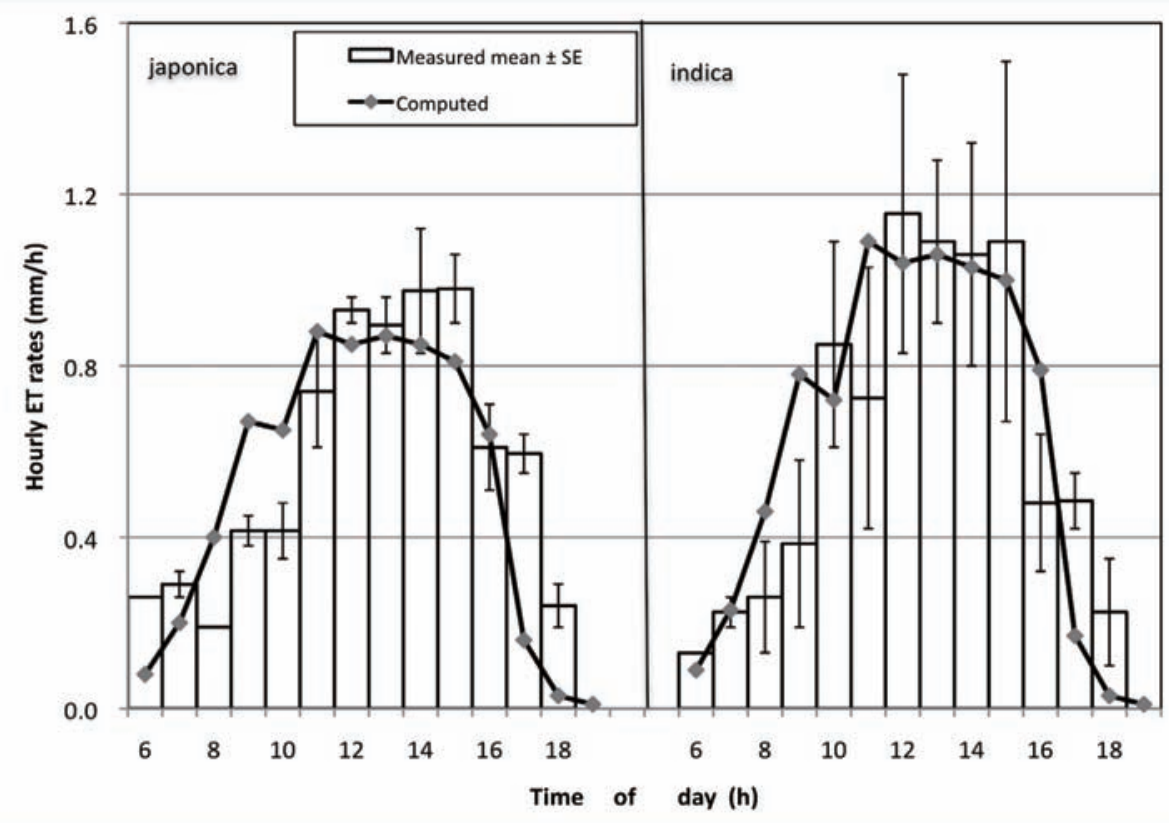

Fig. 1. Comparisons of diurnal change in measured and computed ET rates from a japonica (Nipponbare) and an indica (IR36) for NIAS experiment on September 1, 1982. Measured values are mean \pm one standard error (SE) of two field replicates (two microlysimeters). 


\section{- IRRI $\triangle$ NIPPONBARE $\quad$ IR36}
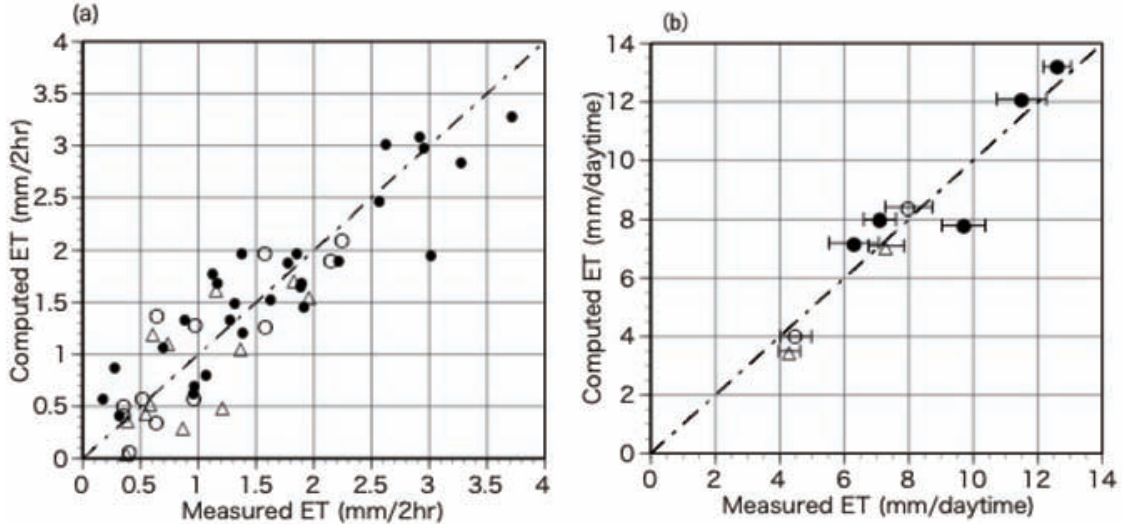

Fig. 2. Comparison of computed and measured ET rates on an hourly (a) and a daytime (b) basis. Two cultivars (Nipponbare and IR36) were used in NIAS experiment, and one (IR 36) in IRRI experiment. Measured values are the means of two replicates \pm one standard errors (SE) in (b). SE are not shown in (a) for clarity (See Fig. 1 for the magnitude of SE).
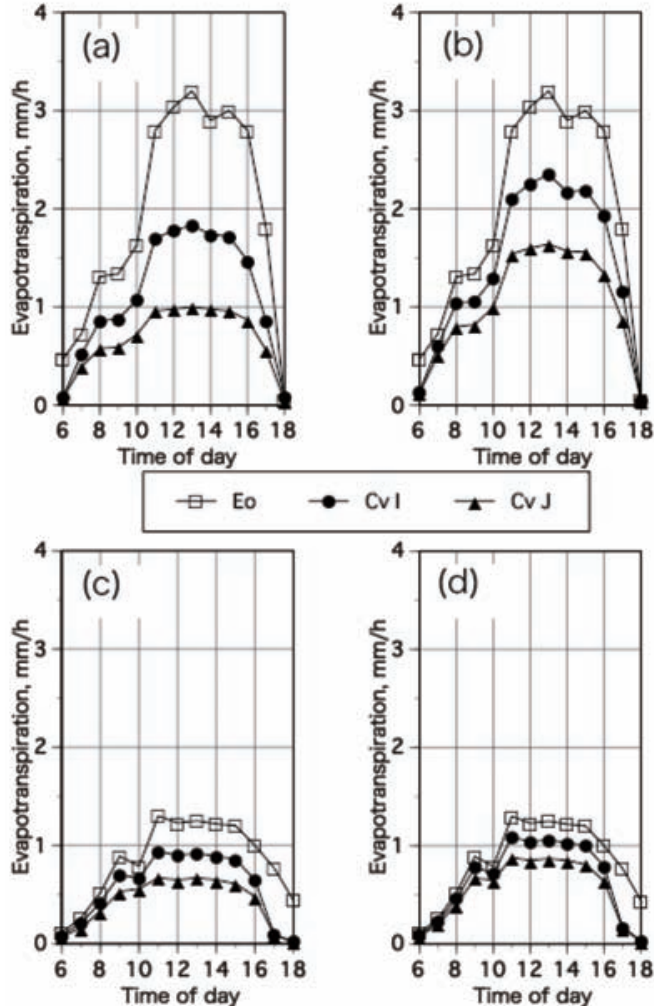

Fig. 3. Simulated ET rates in dry tropical (top) and humid temperate conditions (bottom) from a crop with $L A I$ of 2 (a, c) and a crop with $L A I$ of 4 (b, d). microlysimeter used in this study is insufficient to detect hourly ET, especially when the atmospheric demand is low. The resolution of the instrument was $0.3 \mathrm{~mm}$, whereas the combination method can determine the ET as low as $0.1 \mathrm{~mm}$. Microlysimetry is also subject to large variation among instruments, as the large standard error (SE) indicates (Fig. 1). The reason for this is that an instrument can accommodate only two to three plants so variations in plant size are reflected directly.

\subsection{Implications of the model}

There are three distinct features to be noted in the simulation results (Fig. 3). First, for an obvious reason, a denser crop, i.e., a crop with higher $L A I$ evaporates during daytime at a rate close to the potential than a less dense crop. ET of Cv I with $L A I$ of 4 , for instance, is higher than that with $L A I$ of 2 by $26 \%$ on daytime basis under the same atmospheric demand in the arid, tropical conditions. Second, all the crops, regardless of cultivars and $L A I$, evaporated at a higher rate relative to the potential in a humid, temperate climate than in an arid, tropical climate. Daytime ET of Cv I with $L A I$ of 4 , for instance, was $86 \%$ of the potential in the temperate summer, whereas it was $75 \%$ in the dry tropical conditions. This result agrees with field observations reported by Takami and O'Toole (1983). Third, Cv I always evaporated at a higher rate than Cv $\mathrm{J}$ when the same atmospheric demand was imposed. 
Table 3. Simulated ET, Rc and degree of stomatal opening (DSO) as a function of location, $L A I$ and cultivar. Daytime mean or total.

\begin{tabular}{lccrccc}
\hline Location & LAI & Cultivar & $\begin{array}{c}\text { ET } \\
(\mathrm{mm} / \mathrm{d})\end{array}$ & ET/Eo & $\begin{array}{c}\text { Rc } \\
(\mathrm{s} / \mathrm{min})\end{array}$ & $\mathrm{DSO}^{*}$ \\
\hline IRRI & 2 & Cv J & 8.7 & 0.35 & 52.1 & 0.82 \\
& 2 & Cv I & 14.5 & 0.59 & 19.9 & 0.88 \\
& 4 & Cv J & 13.3 & 0.54 & 24.2 & 0.88 \\
& 4 & Cv I & 18.3 & 0.74 & 10.0 & 0.87 \\
NIAS & 2 & Cv J & 5.5 & 0.49 & 54.2 & 0.78 \\
& 2 & Cv I & 7.3 & 0.66 & 27.3 & 0.71 \\
& 4 & Cv J & 7.1 & 0.64 & 30.1 & 0.64 \\
& 4 & Cv I & 9.5 & 0.85 & 9.1 & 0.96 \\
\hline
\end{tabular}

$* \mathrm{DSO}=(1 / R c) /(1 / R \min )=R \min / R c$

Such difference was more distinct in the dry tropical conditions than in the humid temperate summer. These findings also reflect our field observations (Fig 1; Sakuratani and Horie, 1985).

The results mentioned above reflect the varying degrees of importance that are exerted by the stomatal resistance across environments and cultivars. As also suggested by daytime average $R c$ (Table 3), the role of crop resistance in ET was more important in a dry, tropical than in a humid temperate climate. However, this was not because the $R c$ itself was greater but because its magnitude relative to $R a$ was greater under our conditions. Our conditions were such that $R a$ at IRRI was about half that at NIAS. It is interesting to note that, for a given cultivar, $R c$ itself was generally larger in the temperate, humid conditions we used. In other words, stomata were on daytime average more open in the dry, tropical conditions with higher atmospheric demand.

Table 3 also suggests that the role of $R c$ was more important in $\mathrm{Cv} \mathrm{J}$ than in $\mathrm{Cv}$ I. The $R c$ of $\mathrm{Cv} \mathrm{I}$ was generally less than half that of $\mathrm{Cv}$ J. Again, this does not necessarily mean that $\mathrm{Cv}$ I's stomata were more open during the daytime. Differences in the degree of opening were not consistent, and it was the difference in Rmin that brought about large differences in $R c$ between the two cultivars. Thus, it is likely that the higher canopy conductance $(1 / R c)$ associated with higher yield and crop growth rate among wide range of rice genotypes (Horie et al., 2006) is due to their higher maximum leaf stomatal conductance (1/Rmin). A similar trend can be seen in a broader ecological context, as summarized by Jones (1992). Productive plants in general have higher 1/Rmin and thus higher canopy conductance $(1 / R c)$, thereby taking up $\mathrm{CO}_{2}$ and using water to the extent possible when the water supply is not limited.

\section{Conclusions}

The model developed here worked satisfactorily to predict ET rates from irrigated rice under both dry tropical and humid temperate climates. Calculated ET rates were in good agreement with the measured ones on a daytime basis. Although the results of hourly comparisons were less satisfactory, we could expect better agreement if both lysimetry as well as the estimates of the net radiation and aerodynamic properties are improved.

Our study has shown that the crop resistance $R c$ in irrigated rice is primarily determined by Rmin and LAI. This is because, as the degree of stomatal opening on a daily basis suggests, rice stomata are nearly fully open in most situations. But this is not to say that $R c$ does not play an important role in ET from irrigated rice. Actual ET relative to the potential was reduced to be 35 to $85 \%$, depending on the magnitude of $R c$ relative to $R a$. Thus equally important are the wind speed and the aerodynamic properties of the crop that determine $R a$.

This study provides important clues to issues about crop ET from irrigated rice. Higher ET rates generally observed in high-yielding cultivars are probably due to their lower Rmin than that of less productive ones. Furthermore, the strong wind that generally prevails in a tropical dry season makes stomatal control of ET more significant than in a calm, temperate summer. We 
therefore conclude that our simple approach in which the combination formula is coupled with the SRF is capable of analyzing and predicting the significance of stomatal control on ET from irrigated rice fields.

\section{Acknowledgements}

We thank Dr. T. C. Carlson, Pennsylvania State University, for his helpful comments on the manuscript. Constructive comments from the two reviewers are also appreciated.

\section{References}

Bouman, B. A. M., Kropff, M. J., Tuong, T. P., Wopereis, M. C. S., Ten Berge, H. F. M., and Van Laar, H. H., 2001 : ORYZA2000: modeling lowland rice. International Rice Research Institute, Los Baños, Philippines, and Wageningen University and Research Centre, Wageningen, Netherlands, 235 pp.

Campbell, G. S., and Norman, J. M., 1998: An Introduction to Environmental Biophysics, Springer, New York, 286 pp.

Damour, G., Simonneau, T., Cochard, H., and Urban, L., 2010: An overview of models of stomatal conductance at the leaf level. Plant, Cell and Environ., 33, 1419-1438.

Gerosa, G., Mereu, S., Finco, A., and Marzuoli, R., 2012: Stomatal conductance modeling to estimate the evapotranspiration of natural and agricultural ecosystems. In Evapotranspiration-Remote Sensing and Modeling (ed. by Irmak A.). ISBN: 978-953307-808-3, InTech, (available from: http://www.intechopen.com/book/evapotranspiration -remote-sensing-and-modeling/stomatal-conductancemodeling-to-estimate-the-evapotranspiration-ofnatural-and-agricultural-ecosyst) .

Horie, T., 1980: Studies on photosynthesis and primary production of rice plants in relation to meteorological environments. III A model for the simulation of net photosynthesis, transpiration and temperature of a leaf and test of its validity. J. Agric. Meteorol., 35, 201-213.

Horie, T., Matsuura, S., Takai, T., Ohsumi, A., and Shiraiwa, T., 2006: Genotypic difference in canopy diffusive conductance measured by a new remote- sensing method and its association with the difference in rice yield potential. Plant, Cell and Environ., 29, 653-660.

Jarvis, P. G., 1976: The interpretation of the variations in leaf water potential and stomatal conductance found in canopies in the field. Phil. Trans. R. Soc. Lond. B, 273, 593-610.

Jones, J. W., Hoogenboom, G., Porter, C. H., Boote, K. J., Batchelor, W. D., Hunt, L. A., Wilkens, P. W., Singh, U., Gijsman, A. J., and Ritche, J. T., 2003: The DSSAT cropping system model. Eur. J. Agron., 18, 235-265.

Jones, H. G., 1992: Plants and Microclimate. Cambridge University Press, Cambridge University Press, Cambridge, 456 pp.

Maruyama, S., Kabaki, N., and Tajima, K., 1985: Water consumptions in Japonica and Indica rice varieties. Jpn J. Crop Sci., 54. 32-38.

Monteith, J. L., 1965: Evaporation and environment. Symp. Soc. Exp. Biol. 19, 205-234.

Monteith, J. L., and Unsworth, M. H. 2008: Principles of Environmental Physics (third edition). American Elsevier, Publishing Company, Inc., New York, 418 pp.

Sakuratani, T., and Horie, T., 1985: Studies on evapotranspiration from crops, (1) On seasonal changes, varietal differences and the simplified methods of estimate in evapotranspiration of paddy rice. $J$. Agric. Meteorol., 41, 45-55.

Stewart, J. B., 1988: Modeling surface conductance of pine forest. Agric. For. Meteorol., 43, 19-35.

Takami, S. and O’Toole, J. C., 1983: Evapotranspiration from irrigated rice in the tropical dry season. $J$. Agric. Meteorol., 39, 191-200.

Tomar, V. S. and O’Toole, J. C., 1980: Design and testing of a microlysimeter for wetland rice. Agron. J., 72, 689-692.

Uchijima, Z., 1976: Microclimate of the rice crop. In Climate and Rice. International Rice Research Institute, Los Baños, Philippines, pp. 115-140.

Van Bavel, C. H. M., 1966: Potential evaporation: the combination concept and its experimental verification. Water Resour. Res., 2, 455-467. 